\title{
The effect of long-term working memory through personalization applied to free recall: Uncurbing the primacy-effect enthusiasm
}

\author{
Alessandro Guida • Doriane Gras • Yvonnick Noel • \\ Olivier Le Bohec · Christophe Quaireau • Serge Nicolas
}

Published online: 8 January 2013

(C) Psychonomic Society, Inc. 2013

\begin{abstract}
In this study, a personalization method (Guida, Tardieu, \& Nicolas, European Journal of Cognitive Psychology, 21: 862-896 2009) was applied to a freerecall task. Fifteen pairs of words, composed of an object and a location, were presented to 93 participants, who had to mentally associate each pair and subsequently recall the objects. A 30-s delay was introduced on half of the trials, the presentation rate was manipulated ( 5 or $10 \mathrm{~s}$ per item), and verbal and visuospatial working memory tests were administered to test for their effects on the serial curve. Two groups were constituted: a personalized group, for whom the locations were well-known places on their university campus, and a nonpersonalized group, for whom the locations did not refer to known places. Since personalization putatively operationalizes long-term working memory (Ericsson \& Kintsch, Psychological Review, 102: 211-245 1995) - namely, the capacity to store information reliably and rapidly in long-term memory - and if we take a dualstore approach to memory, the personalization advantage would be expected to be greater for pre-recency than for recency items. Overall, the results were compatible with
\end{abstract}

Electronic supplementary material The online version of this article (doi:10.3758/s13421-012-0284-3) contains supplementary material, which is available to authorized users.

A. Guida $\cdot$ Y. Noel $\cdot$ O. Le Bohec $\cdot$ C. Quaireau

Université Rennes 2, Rennes, France

D. Gras $\cdot \mathrm{S}$. Nicolas

Université Paris Descartes, Paris, France

A. Guida $(\bowtie)$

Centre de Recherche en Psychologie, Cognition et Communication, Université Rennes 2 - Haute Bretagne, Place du Recteur

Henri Le Moal CS 24 307, Bâtiment S - Bureau S 509,

35043 Rennes Cedex, France

e-mail: alessandro.guida@univ-rennes2.fr

A. Guida

e-mail: alessandro.guida.psychology@gmail.com long-term working memory theory. They contribute to validating the personalization method as a methodology to characterize the contribution of long-term memory storage to performance in working memory tasks.

Keywords Working memory · Long-term working memory · Personalization $\cdot$ Free recall

As has been stated by Rose, Myerson, Roediger, and Hale (2010), recent influential theories of working memory (WM) have been built around the link between long-term memory (LTM) and WM, postulating that WM is the activated portion of LTM (e.g., Anderson, Reder, \& Lebiere, 1996; Barrouillet, Bernardin, \& Camos, 2004; Cowan, 1995; Just \& Carpenter, 1992; Oberauer, 2002). As compared to Baddeley's 1986 model (but for an amendment, see Baddeley, 2000), they could be coined LTM-based WM models. The advantages that stem from this principle include the link between WM and LTM, facilitating the accounts of numerous studies demonstrating the effects of LTM knowledge on WM (e.g., Hambrick \& Engle, 2002; Hambrick \& Oswald, 2005; Hulme, Maughan, \& Brown, 1991; Hulme, Newton, Cowan, Stuart, \& Brown, 1999; Poirier \& Saint Aubin, 1995).

Mutatis mutandis, some models - which could be coined LTM storage-based WM models-have gone further, by suggesting that WM performance is due not only to LTM activation or the process of reconstructing LTM activation from LTM knowledge (see the reintegration process of Schweickert [1993] or Towse, Cowan, Hitch, \& Horton's [2008] more recent reconstruction hypothesis for WM), but also to direct storage and retrieval of information from episodic LTM. Taking this line, Unsworth and Engle (2007) proposed a dual-component model to account for differences in WM capacity. Their model incorporates a primary memory, comparable to short-term memory (STM), and a secondary memory, which corresponds to 
LTM. A similar dichotomy was put forward earlier by Ericsson and Kintsch (1995), who proposed a short-term working memory (ST-WM) and a long-term working memory (LT-WM).

The aim of this study is to put forward a methodpersonalization - that allows for characterizing the contribution of LTM storage to performance in WM tasks. In this introduction, we will first describe our theoretical framework and then our method, and we will finish by introducing the study.

\section{The long-term working memory framework}

One important difference between Ericsson and Kintsch's (1995) theory and other LTM storage-based WM models (e.g., Unsworth and Engle's [2007] theory, Cowan's [1995] "virtual short-term memory," or Was and Woltz's [2007] "available long-term memory") is the hypothesis that the ability to use LTM encoding and retrieval in WM tasks is a function of one's expertise in a given domain and task. More specifically, only when specific cognitive structures - retrieval structures - have been built up through practice can new information be transferred rapidly and reliably into LTM (for physiological evidence, see Guida, Gobet, Tardieu, \& Nicolas, 2012; for theoretical considerations, see Ericsson \& Kintsch, 2000; Gobet, 2000a, 2000b). This type of model can be coined expertise-dependent LTM storage-based WM model (see the template theory for another exemplar: Gobet \& Simon, 1996b). These kinds of models easily explain why experts in various domains outperform novices when WM or STM tasks are adapted to their domain of expertise (e.g., abacus use, Hatano \& Osawa, 1983; aircraft piloting, Gobet \& Simon, 1996b; Sohn \& Doane, 2003; the game of Go, Masunaga \& Horn, 2000; text comprehension, Guida \& Tardieu, 2005; reading span, Postal, 2004; and written production, Kellogg, 2001).

The loci (Latin for "locations") method (Yates, 1966) is a good example to demonstrate how retrieval structures can be used. In the following example, the method uses knowledge of one's own house. Imagine that you were asked to recall a list of aurally presented objects. You could start by mentally picturing yourself at your front door and then take a mental tour of the house, linking each object to a particular place. During the recall phase, you would just have to follow the same route to retrieve each object. In this example, the retrieval structure is the visuospatial knowledge of your house, and each location is a retrieval cue. All retrieval structures have the same purpose, namely to accelerate the transfer of information from STM/WM to LTM. Therefore, the capacity to use LTM in WM tasks - that is, LT-WM-is a function of one's expertise in a given domain.

\section{The personalization method}

In this theoretical context, personalization can be used to manipulate expertise, capitalizing on the method of loci. As described above, our visuospatial knowledge of well-known places (house, university, etc.) is a good example of a retrieval structure. Following this approach, Guida et al. (2009, Exp. 2) adapted a reading span task (Daneman \& Carpenter, 1980) to mirror the loci method. As in classic reading span tasks, the authors presented sequences of sentences to the participants, who had to read them aloud and at the end of each sequence recall the last word of each sentence. However, the authors inserted a location into each sentence (e.g., "the university cafeteria," "the university library"), each sentence finished with an object. As in the classic procedure, participants had to read the sentences aloud and at the end of each sequence to recall the last words - in this case, the objects. To manipulate expertise, one group of participants (the personalized group) read a text prior to the task suggesting that each sentence described a place that they knew well in Paris; for example, "the university cafeteria" was supposed to be interpreted as being at the Université Paris Descartes where they were students. Conversely, participants in the nonpersonalized group were encouraged to imagine that the sentences described places in Erevan (Armenia); in this case, "the university cafeteria" was supposed to be interpreted as being at an unknown Armenian university. Through this paradigm, the authors hoped that the personalized group would be able to use the well-known locations as retrieval structures to accelerate the transfer into LTM of the objects to be remembered, and therefore to expand their WM capacity as measured by the reading span task. The results supported this hypothesis, showing among other things a superiority of the personalized group, which was interpreted as a contribution of LTM storage to WM performance.

\section{Location personalization and the self-reference effect}

It is important to stress that the personalization task used by Guida et al. (2009) is peculiar and specifically targets locations (it could be coined location personalization), with the aim of mirroring the effect of the method of loci. We do not think that this kind of personalization can be linked to the self-reference effect (Rogers, Kuiper, \& Kirker, 1977), whereby information encoded with reference to the self improves memory performance, as compared to semantic encoding, for example (e.g., Bellezza, 1984; Kuiper \& Rogers, 1979; for a review, see Symons \& Johnson, 1997). The main reason for this is that location personalization closely mirrors the method of loci, and to our knowledge, 
the method of loci has not been linked to the self-reference effect. We see at least two good reasons for this.

The first is that locations, even if they are very familiar, do not appear to be central features of the self. And the second reason-most crucial-is that self-reference procedures and the method of loci (or location personalization) differ at a crucial point: In self-reference procedures, participants are asked to process $a$ word, saying whether or not it is part of the self, and are then asked to recall or recognize that word. Conversely, in the case of the location personalization paradigm (or method of loci), it is not the word that is (putatively) related to the self (i.e., the location) that has to be recalled or recognized, but an object that is not well known and has not been personalized. In other words, in the location personalization paradigm, recall does not concern a part of the self, which is exactly the purpose of the self-reference procedure.

\section{Applying the personalization method to a free-recall task}

The basic idea of Ericsson and Kintsch's (1995) theory is that WM performance is based on both ST-WM and LTWM. While the former process is limited to three or four elements, like attentional focus (for reviews, see Cowan, 2001, 2005), because it is dependent on attentional resources, the latter can be extended via expertise. Taking this approach, Guida et al.'s (2009) result showing a larger reading span for the personalized as compared to the nonpersonalized group can be interpreted as the supplementary contribution of LT-WM. In other words, while the nonpersonalized group's reading span is constituted mainly by ST-WM, the personalized group's reading span is constituted by both STM and LTM storage (i.e., ST-WM and LT-WM). However, even if this interpretation is based on solid theoretical arguments (for more details, see Guida et al., 2009), it is difficult to prove LTM storage with a WM task. A further step to ascertain this interpretation would be to use a task that allows for separating STM from LTM storage and to establish that personalization indeed allows for increasing only LTM storage. Several studies by Unsworth and colleagues (e.g., Unsworth \& Engle, 2007; Unsworth, Spillers, \& Brewer, 2010) have shown that free-recall tasks, and specifically studying recency and primacy effects (or pre-recency), can be useful for investigating how WM capacities are related, respectively, to STM and LTM components. On the basis of the classic STM-LTM dual approach to human memory (for a case in favor of this approach, see Davelaar, Goshen-Gottstein, Ashkenazi, Haarmann, \& Usher, 2005 ; but for opposite, single-store models of memory, see Brown, Neath, \& Chater, 2007; Howard \& Kahana, 1999, 2002; Nairne, Neath, Serra, \& Byun, 1997), Unsworth and colleagues showed that the difference between high-WM-span individuals and low-WM- span individuals in terms of recency and pre-recency effects mainly concerned the pre-recency part of the curve, which is supposed to reflect LTM storage (the recency part of the serialposition curve reflects STM storage). We therefore decided to apply the personalization paradigm (Guida et al., 2009, Exp. 2) to a free-recall task using the same classic STMLTM approach, with the intent to demonstrate that personalization would increase only the capacity to store in LTM. In other words, the advantage of personalization was predicted to vary according to serial position, with an increase of recall restricted to the pre-recency items.

Applying the personalization method to a free-recall task took the following form: Participants were presented with 15 pairs of words composed of a location - similar to those in Guida et al. (2009, Exp. 2) - and an object during a presentation phase. Their task was to mentally associate each location with each object, and subsequently to recall only the objects during the recall phase. However, in order to ensure that participants correctly mentally associated each location with each object in the presentation phase and were not tempted to focus only on the objects, the participants also had to perform an object-location recognition task just after the recall phase to a level above a threshold.

Following Guida et al.'s (2009, Exp. 2) personalization paradigm, before the presentation phase, half of the participants (personalized group) read a text indicating that the locations were in the participants' university, while the other half (nonpersonalized group) read a text indicating that the locations were in Armenia.

Concerning the link between objects and locations, one element bears mentioning. The objects and locations in our 15 word pairs were not associated on a one-to-one basis; three objects were paired with the same location (for examples, see Table 1), which allowed us to present the locations in two ways: chunked (the same location was displayed three times consecutively with three different objects), and unchunked (five locations were displayed consecutively, three times in a row). The chunked presentation was expected to increase recall, due to the objects being processed as chunks (e.g., Cowan, Chen, \& Rouder, 2004; Gobet et al., 2001). It has been well established that chunking enhances both short-term retention (e.g., with novices, Chen \& Cowan, 2005; Cowan et al., 2004; and with experts, Gobet \& Simon, 1996a, 1996b) and long-term learning (e.g., Gobet \& Simon, 1996b, Exp. 3; Jones, Gobet, \& Pine, 2007, 2008). Moreover, the chunking was expected to impact recall performance differentially according to personalization and serial position, accentuating the interaction between these two variables, which corresponds to an interaction between chunking, personalization, and serial position. The rationale underlying this hypothesis was that the chunked presentation would favor an integrated representation of the three objects for each location (e.g., Radvansky \& Zacks, 1991), which would help to more 
efficiently link the objects to each location, since this linking process in the case of the personalized locations would be expected to enhance encoding and retrieval from LTM.

In addition to personalization, we also included factors that traditionally have different impacts at the extremities of the serial curve. We manipulated the delay between the end of the presentation phase and the recall phase. This should mainly affect the recency part of the curve (an effect known at least since Craik, 1970; Gardiner, Thompson, \& Maskarinec, 1974;
Glanzer \& Cunitz, 1966). Symmetrically, the presentation rates were also manipulated, in order to affect only the pre-recency part of the curve (an effect known at least since Glanzer \& Cunitz, 1966; Roberts, 1972). Delay and presentation rate were manipulated for several reasons. The first was to check whether, with our unusual experimental paradigm - that is, location personalization - classical serial position effects would still be found. Second, presentation rate was also manipulated in order to accentuate the personalization effect, by slowing down the

Table 1 An example of object-location pairings displayed during the presentation phase, with both unchunked and chunked presentation

\begin{tabular}{|c|c|c|c|}
\hline List 1 & List 2 & List 3 & Objects \\
\hline \multicolumn{4}{|l|}{ Unchunked Locations } \\
\hline $\begin{array}{l}\text { A computer room } \\
\text { (Une salle informatique) }\end{array}$ & $\begin{array}{l}\text { The subway station platform } \\
\text { (Le quai de la station de métro) }\end{array}$ & $\begin{array}{l}\text { The university cafeteria } \\
\text { (La cafétéria de l'université) }\end{array}$ & Obj. 1 \\
\hline $\begin{array}{l}\text { A university toilet } \\
\text { (Une toilette de l'université) }\end{array}$ & $\begin{array}{l}\text { The exit staircase of the subway } \\
\text { (L'escalier de sortie du métro) }\end{array}$ & $\begin{array}{l}\text { In front of a coffee machine } \\
\text { (Devant une machine à café) }\end{array}$ & Obj. 2 \\
\hline $\begin{array}{l}\text { A classroom (Une salle de cours } \\
\text { de l'université) }\end{array}$ & $\begin{array}{l}\text { The university library (La bibliothèque } \\
\text { de l'université) }\end{array}$ & $\begin{array}{l}\text { The university bookstore } \\
\text { (La librairie de l'université) }\end{array}$ & Obj. 3 \\
\hline $\begin{array}{l}\text { The university music building } \\
\text { (Le bâtiment musique de l'université) }\end{array}$ & $\begin{array}{l}\text { The university registrar's office } \\
\text { (La scolarité de l'université) }\end{array}$ & $\begin{array}{l}\text { The university sport field } \\
\text { (Le terrain de sport de l'université) }\end{array}$ & Obj. 4 \\
\hline $\begin{array}{l}\text { The university bus stop } \\
\text { (L'arrêt de bus de l'université) }\end{array}$ & $\begin{array}{l}\text { The university lecture theatre } \\
\text { (Un amphithéâtre de l'université) }\end{array}$ & $\begin{array}{l}\text { The university car park } \\
\text { (Le parking de l'université) }\end{array}$ & Obj. 5 \\
\hline A computer room & The subway station platform & The university cafeteria & Obj. 6 \\
\hline A university toilet & The exit staircase of the subway & In front of a coffee machine & Obj. 7 \\
\hline A classroom & The university library & The university bookstore & Obj. 8 \\
\hline The university music building & The university registrar's office & The university sport field & Obj. 9 \\
\hline The university bus stop & The university lecture theatre & The university car park & Obj. 10 \\
\hline A computer room & The subway station platform & The university cafeteria & Obj. 11 \\
\hline A university toilet & The exit staircase of the subway & In front of a coffee machine & Obj. 12 \\
\hline A classroom & The university library & The university bookstore & Obj. 13 \\
\hline The university music building & The university registrar's office & The university sport field & Obj. 14 \\
\hline The university bus stop & The university lecture theatre & The university car park & Obj. 15 \\
\hline
\end{tabular}

\begin{tabular}{lll}
\hline List 4 & List 5 & List 6 \\
\hline Chunked Locations & & \\
A computer room & The subway station platform & The university cafeteria \\
A computer room & The subway station platform & The university cafeteria \\
A computer room & The subway station platform & The university cafeteria \\
A university toilet & The exit staircase of the subway & In front of a coffee machine \\
A university toilet & The exit staircase of the subway & In front of a coffee machine \\
A university toilet & The exit staircase of the subway & In front of a coffee machine \\
A classroom & The university library & The university bookstore \\
A classroom & The university library & The university bookstore \\
A classroom & The university library & The university bookstore \\
The university music building & The university registrar's office 3 \\
The university music building & The university registrar's office & The university sport field \\
The university music building & The university registrar's office & The university sport field \\
The university bus stop & The university lecture theatre & The university sport field \\
The university bus stop & The university lecture theatre & The university car park \\
The university bus stop & The university lecture theatre & The university car park \\
\hline
\end{tabular}

The locations were given in French, which is shown in parentheses. 
rate from 5 to $10 \mathrm{~s}$. The rationale was that, if participants had more time to encode the objects by using the locations, the differential effect of personalization on the first part of the curve would increase. Hence, an interaction was expected between serial position, personalization, and presentation rate. Third, with regard to the delay, we wanted to include a factor that would influence the recency part of the curve, since personalization and presentation rate were expected to influence only the primacy part. Hence, no interaction was expected between personalization, serial position, and delay.

To conclude, two WM tests were used to test the effect of WM capacity on free recall. Because the LT-WM theory (Ericsson \& Kintsch, 1995) assumes that the difference between high- and low-WM-span individuals is due to the capacity to store in LTM, we expected the advantage of high-span individuals to vary with the serial positions of the items, in a similar way to that of personalization.

\section{Method}

\section{Participants}

The participants were 93 undergraduate students at Université Rennes 2. All were native French speakers (mean age 21.05 years, $S D=2.99$ ).

\section{Material}

\section{Free recall and recognition test materials}

For the common presentation phase of the free-recall test and the recognition test, six homogeneous lists of 15 objects (see Table 1 in the supplementary materials) were created. The syllabic length, word frequency (using the French database Lexique 3.71; see New, Pallier, Brysbaert, \& Ferrand, 2004), and imageability (using the Canadian database Omnilex; see Desrochers \& Bergeron, 2000) of the objects were controlled. The order of the objects in the presentation phase was counterbalanced across participants. To create object-location pairs, we used 15 generic university locations (e.g., cafeteria and library; see Table 1 for all of the locations). These 15 locations had previously been selected via a questionnaire given to another sample of students at the university. It was crucial to have locations that would have a high probability of being very familiar to all of the participants, as is the case when one chooses familiar locations in the method of loci (e.g., Roediger, 1980). The associations between the objects and the locations for each of the six lists were not one-to-one. Instead, only five locations were used for each list of 15 objects. In other words, within each list, three objects were associated with the same location (for examples, see Table 1). This corresponded to the item/cue ratio that can be observed with experts in free-recall tasks-for example, the participant known as S.F. used to operate with three or four items that were linked to one spatial cue (Chase \& Ericsson, 1982; Ericsson, 1985). The order of presentation of the five locations in the presentation phase was counterbalanced across trials and participants. Two ways of displaying the locations were used: The same location could be displayed three times consecutively with three different objects (chunked presentation, Table 1), or five different locations could be displayed consecutively, three times in a row (unchunked presentation, Table 1). This constituted the Chunking factor.

For the recognition phase of the recognition test, the materials comprised ten object-location pairs; five pairs were taken from the presentation phase (and were expected to be recognized), and five were lures. The five pairs from the presentation phase involved five different locations. The objects were selected at random among the three objects that had been associated with each location during the presentation phase. The lures were also composed of five different locations, and each object was randomly selected among the objects that were not associated during the presentation phase with each location, following a supplementary rule: The five objects in the lures had to come from five different locations. In other words, two objects in the lures could not have been associated with the same location during the presentation phase.

\section{WM test materials}

Verbal WM task This task was constructed using the French version (Desmette, Hupet, Schelstrate, \& van der Linden, 1995) of Daneman and Carpenter's (1980) reading span test, adapted for use on a computer using E-Prime software (Psychology Software Tools Inc., Sharpsburg, PA). The same version had been used in Guida et al.'s (2009) study. The task included five sequences corresponding to five sentence levels: from a two-sentence to a six-sentence level. The first level had two sentences with three trials (total of six sentences); the second had three sentences with three trials (total of nine sentences), and so on, up to six sentences with three trials (total of 18 sentences). In total, 60 sentences were used for each reading span test.

Visuospatial WM task A symmetry span task was used (Unsworth, Heitz, Schrock, \& Engle, 2005). The participants had to recall sequences of red squares that appeared in a $4 \times 4$ matrix. Before each red square was presented, a symmetry judgment task was carried out in which participants had to indicate whether a black-and-white figure displayed on an $8 \times 8$ matrix was vertically symmetrical by pressing the "a" key for "yes" and the "p" key for "no" (on an AZERTY keyboard). The structure of the task was identical to that of the reading span task, with five sequences 
corresponding to five levels of "judgment + red square to be remembered" (from two to six "judgments + red squares to be remembered").

\section{Procedure}

\section{Free-recall and recognition test procedure}

The participants were tested individually in the presence of an experimenter. They sat in front of a computer screen on which the instructions for the recall and recognition tests were displayed. Before the test phase started, they were familiarized with the recall and recognition tasks. Word pairs were displayed in black on a white background (size 18 in Courier New font). Each of the six trials began with a message that the presentation phase was about to start, and then the experimenter pressed a button. After $100 \mathrm{~ms}$, the first "object + location" pair was displayed, with the object on the left of the screen and the location on the right. The duration of the display was 10 or $5 \mathrm{~s}$, depending on the condition of the Presentation Rate factor. We selected this range in line with a review (Verhaeghen \& Kliegl, 2000) showing that studies using the method of loci have usually used presentation times of $5.00 \mathrm{~s}$ and longer (e.g., Bellezza \& Reddy, 1978; De Beni \& Cornoldi 1985, 1988; Roediger, 1980; Ross \& Lawrence, 1968). This is done because, with shorter times, it is difficult to retrieve the location and to form a mental representation of the location and the object. For each participant, the first three trials were displayed with one type of chunking presentation, while the last three were presented with the other type.

After 15 pairs had been displayed, and for half of the trials (three out of six, corresponding to the delayed condition), a message announcing an interference task appeared. This was a 30-s task in which participants had to count backward in threes or fours from a three-digit number. "Three" or "four" were prompted (randomly) on the screen every $3 \mathrm{~s}$ to indicate the kind of subtraction to be carried out. On the other half of the trials, no delay was added.

After a delay or directly after the presentation phase, depending on the condition of the Delay factor, a message prompting the participant to recall all of the objects was displayed, and the experimenter wrote down the recalled objects. The limit for recall time was set at $100 \mathrm{~s}$. After that time, a message that the recognition task was going to start appeared. The experimenter then pressed a button, and ten word pairs (object + location) were randomly displayed. For each pair, the participant had to indicate whether the object and the location had been displayed together during the previous presentation phase by pressing the "a" key for "yes" and the "p" key for "no" (on an AZERTY keyboard).

For each participant, this procedure was repeated six times, once for each of the six lists, followed by the two
WM tests. The order of presentation of these tests was counterbalanced across participants.

\section{WM task procedure}

Instructions for the reading span task were displayed on the computer screen. Participants were asked to read aloud the sentences displayed at their own pace and to memorize the last word of each sentence. The sentences appeared one at a time, in sets of two, three, and up to six, starting with two. When a participant pronounced the last word of a sentence, the following sentence appeared on the screen. At the end of the last sentence of each set, rappel (French for "recall") was displayed on the screen. Participants then had to recall the last word of each sentence in the set. Three trials were presented at each level. To move on to a more difficult set in terms of number of sentences, participants had to correctly recall the last words of two trials (if the first two trials were correctly performed, the third was also displayed). If a participant did not succeed, the test was stopped.

The last level at which a participant performed two out of three trials correctly was taken as a measure of the reading span, corresponding to the set before last. Half a point was added if the participant was correct on one out of three trials for the last set.

For the visuospatial reading task, the procedure was the same, except that instead of reading a sentence and remembering the last word, participants had to make a symmetry judgment concerning an $8 \times 8$ matrix and then remember the location of a red dot that was displayed in a $4 \times 4$ matrix for $650 \mathrm{~ms}$. As in the reading span task, participants had to recall all of the elements to be remembered at the end of each set. To do so, an empty $4 \times 4$ matrix appeared, and participants had to recall the sequence of red-square locations by pointing successively at the right locations.

\section{Design and statistical analysis}

The dependent variable was binary, set to 0 if an object was not correctly recalled and 1 if it was. Consequently, we used a binomial distribution to analyze the effects (for problems with the use of analyses of variance [ANOVAs] for the analysis of categorical data, see Jaeger, 2008; Quené \& van den Bergh, 2008) of two between-subjects factors, Personalization (nonpersonalized vs. personalized) and Presentation Rate (5 vs. 10 s), and two within-subjects factors, Delay (no delay vs. delay) and Chunking (chunked information vs. unchunked information). For both betweensubjects factors, participants were assigned randomly.

The serial position of the items was treated as a continuous numerical variable modeled by the equation $a x^{2}+b x+$ $c=0$. Statistical analysis was computed using both the linear serial position variable and its quadratic transform as 
predictors. The interactions of serial positions with the other variables were also analyzed through the linear component and the quadratic component.

In a supplementary analysis, we introduced one external measure-WM span - by averaging the $z$ scores of verbal and visuospatial WM tasks, to test the LT-WM predictions concerning the kind of interaction likely to be observed between this variable and the serial positions. However, to make this interaction graphically transparent (for an example, see Oberauer, 2005), a median split was executed (only in the figures) to divide participants into two groups: those with high and low spans. In terms of averaged $z$ score WM span, neither the personalization groups nor the presentation rate groups differed statistically. Concerning personalization, the mean averaged $z$ score was $-0.03(S D=0.82)$ for the personalized group versus $0.04(S D=0.74)$ for the nonpersonalized group, $t(73)=0.4$, n.s. Concerning presentation rate, the average span was $-0.12(S D=0.76)$ for the 5 -s group versus 0.13 $(S D=1.15)$ for the 10 -s group, $t(73)=1.44$, n.s.

Statistical analyses were performed by fitting a linear mixedeffects model to recall scores (for similar analyses, see the special issue of Journal of Memory and Language on "Emerging Data Analysis": Vol. 54, Issue 4). Models were fitted using a restricted maximum likelihood technique. The R2STATS (Noel, 2011) package was used, which is based on the lme4 package (Bates, Maechler, \& Bolker, 2011) in R (Version 2.14, CRAN project; R Development Core Team, 2012).

Initially, a model that only included a random factor (participants) was applied to the data (Model 0). This original model was then enriched by adding different variables and the interactions between these variables. Given the binary nature of the dependent variable, the improvement of fit of each model was statistically tested using a likelihood ratio chi-square test. The procedure is very similar to testing for the significance of increments to $R^{2}$ that result from the addition of explanatory variables to a multiple regression equation.

\section{Results}

Results of the recognition task

The purpose of this task was to check that the participants had followed the instructions correctly, focusing not only on the objects to be recalled but also on the association between the objects and locations. We selected only the participants who had executed the task correctly for at least $50 \%$ of the pairs, with a threshold at $p=.05$. The analysis was conducted using a binomial distribution defined by $B(60,0.5)$. The threshold required appeared to be 35 successes out of 60 , corresponding to a hit-false alarm score of .17. Below this score, we considered that participants were guessing at $p=.05$, and consequently 18 of the 93 participants were eliminated. To be complete concerning this task, the mean hit-false alarm score was $.45(S D=.3)$. The mean reaction time of correct rejections was $2,663.86 \mathrm{~ms}(S D=638.93)$, while the mean reaction time of correct detections was $2,486.53 \mathrm{~ms}(S D=663.33)$.

\section{Results of the recall test task}

As is shown in Table 2, the results revealed a main effect of every factor except Personalization. For the latter factor, the mean recall scores were $.55(S D=.14)$ for the nonpersonalized group and $.59(S D=.18)$ for the personalized group. With regard to presentation rate, the mean recall score was higher with a 10 -s presentation rate $(M=.65, S D=.17)$ than with a 5 -s rate $(M=.5, S D=.11)$. The same advantage was observed for chunked information $(M=.59, S D=.18)$ over unchunked information $(M=.55, S D=.17)$, and for the nodelay condition $(M=.6, S D=.17)$ over the delay condition $(M=.55, S D=.19)$.

With regard to the first-order interactions, serial position and personalization interacted significantly. Figure 1 shows that as one progresses through the serial positions, the gap in terms of recall scores between the personalized and nonpersonalized groups becomes smaller, with a small crossover for the final positions.

The same pattern was observed for the interaction between serial position and presentation rate, as is shown in Fig. 2, but with no final crossover. These two results confirm the hypothesis of greater effects of personalization and presentation rate on the primacy than on the recency (effect) part of the curve.

The last first-order interaction that was significant concerned delay and presentation rate: Delay had more of an effect on recall with a presentation rate of 5 than of $10 \mathrm{~s}$. More precisely, a delay decreased the recall scores from .55 $(S D=.12)$ to $.46(S D=.14)$ at the 5 -s rate, $\chi^{2}(1, N=39)=$ $30, p<.0001, \eta^{2}=.1$, but had no effect at the 10 -s rate, where the recall scores remained at .65 (no delay, $S D=.18$; delay, $S D=.19), \chi^{2}(1, N=36)=0.3$, n.s., $\eta^{2}=0$.

Delay and presentation rate also interacted in a secondorder interaction with serial position. As is shown in Fig. 3, the interaction between delay and serial positions was greater for the 5-s than for the 10-s presentation rate. It is noteworthy that our hypothesis of an interaction between serial position and delay appeared to be true, but only for the 5 -s presentation rate, $\chi^{2}(2, N=39)=$ $14.75, p=.0006, \eta^{2}=.05$, and not for the 10 -s rate, $\chi^{2}$ $(2, N=36)=5$, n.s., $\eta^{2}=.02$.

A significant interaction between personalization, presentation rate, and serial position was also observed. As is shown in Fig. 4, the interaction between personalization and serial position was greater for the 10 -s than for the 5 -s 
Table 2 Results of linear mixed-effects model comparison comprising five variables: Serial position, chunking, delay, presentation rate, and personalization

\begin{tabular}{|c|c|c|c|c|c|}
\hline Model & Fixed Effect & $\chi^{2}$ & $\mathrm{df}$ & $\mathrm{p}$ & $\eta^{2}$ \\
\hline \multicolumn{6}{|l|}{0} \\
\hline 1 & Serial Position & 128.3 & 2 & $<.0001$ & .41 \\
\hline 2 & Chunking & 25 & 1 & $<.0001$ & .08 \\
\hline 3 & Delay & 21.4 & 1 & $<.0001$ & .07 \\
\hline 4 & Presentation Rate & 16.9 & 1 & $<.0001$ & .05 \\
\hline 5 & Personalization & 2 & 1 & .15 & .01 \\
\hline 6 & Serial Position $\times$ Presentation Rate & 22.4 & 2 & $<.0001$ & .07 \\
\hline 7 & Serial Position $\times$ Personalization & 13.8 & 2 & $<.005$ & .04 \\
\hline 8 & Presentation Rate $\times$ Delay & 11 & 1 & $<.0005$ & .04 \\
\hline 9 & Serial Position $\times$ Chunking & 2.3 & 2 & .32 & .01 \\
\hline 10 & Personalization $\times$ Presentation Rate & 2.4 & 1 & .12 & .01 \\
\hline 11 & Serial Position $\times$ Delay & 2.1 & 2 & .35 & .01 \\
\hline 12 & Chunking $\times$ Delay & 1.8 & 1 & .18 & .01 \\
\hline 13 & Presentation Rate $\times$ Chunking & 1.5 & 1 & .22 & 0 \\
\hline 14 & Personalization $\times$ Delay & 1.1 & 1 & .29 & 0 \\
\hline 15 & Personalization $\times$ Chunking & 0 & 1 & .97 & 0 \\
\hline 16 & Serial Position $\times$ Presentation Rate $\times$ Delay & 18 & 2 & $<.0005$ & .06 \\
\hline 17 & Serial Position $\times$ Personalization $\times$ Presentation Rate & 6 & 2 & $<.05$ & .02 \\
\hline 18 & Personalization $\times$ Presentation Rate $\times$ Delay & 6.1 & 1 & $<.05$ & .02 \\
\hline 19 & Serial Position $\times$ Personalization $\times$ Chunking & 5.5 & 2 & .06 & .02 \\
\hline 20 & Serial Position $\times$ Personalization $\times$ Delay & 3.5 & 2 & .18 & .01 \\
\hline 21 & Serial Position $\times$ Presentation Rate $\times$ Chunking & 2.5 & 2 & .29 & .01 \\
\hline 22 & Serial Position $\times$ Delay $\times$ Chunking & 1.9 & 2 & .39 & .01 \\
\hline 23 & Presentation Rate $\times$ Delay $\times$ Chunking & 1.6 & 1 & .21 & .01 \\
\hline 24 & Personalization $\times$ Presentation Rate $\times$ Chunking & 1.2 & 1 & .56 & 0 \\
\hline 25 & Personalization $\times$ Presentation Rate $\times$ Delay $\times$ Chunking & 5.4 & 1 & $<.05$ & .02 \\
\hline 26 & Serial Position $\times$ Presentation Rate $\times$ Chunking $\times$ Delay & 3 & 2 & .22 & .01 \\
\hline 27 & Serial Position $\times$ Personalization $\times$ Presentation Rate $\times$ Chunking & 1.2 & 2 & .55 & 0 \\
\hline 28 & Serial Position $\times$ Personalization $\times$ Presentation Rate $\times$ Delay & 0.8 & 2 & .66 & 0 \\
\hline 29 & Serial Position $\times$ Personalization $\times$ Chunking $\times$ Delay & 0.4 & 2 & .83 & 0 \\
\hline 30 & Serial Position $\times$ Personalization $\times$ Chunking $\times$ Delay $\times$ Presentation Rate & 2.7 & 2 & .27 & .01 \\
\hline
\end{tabular}

All models included participants as random effects. Serial Position refers to the polynomial contrast of serial positions.

presentation rate. Moreover, serial position and personalization did not interact for the 5-s presentation rate, $\chi^{2}(2, N=39)=$ 3.8 , n.s., $\eta^{2}=.01$, while they did for the 10 -s rate, $\chi^{2}(2, N=36)=16.45, p=.0003, \eta^{2}=.05$.

Personalization and presentation rate also had a secondorder interaction with delay. As is suggested by Fig. 5, delay and personalization did not interact at the 10 -s presentation rate, $\chi^{2}(1, N=36)=1.23$, n.s., $\eta^{2}=0$, with no effect of delay at $10 \mathrm{~s}$ for either the personalized group, $\chi^{2}(1, N=19)=1.39$, n.s., $\eta^{2}=0$, or the nonpersonalized group, $\chi^{2}(1, N=17)=$ 0.15 , n.s., $\eta^{2}=0$. Conversely, these factors did interact at the 5 -s presentation rate, $\chi^{2}(1, N=39)=5.52, p=.02, \eta^{2}=.02$, with delay having a greater effect for the nonpersonalized than for the personalized group, with a significant effect in both cases: $\chi^{2}(1, N=22)=6.46, p=.01$, $\eta^{2}=.02$, and $\chi^{2}(1, N=17)=28.91, p<.0001, \eta^{2}=.09$, respectively.

To conclude the second-order interactions, it is important to note that the predicted serial position, personalization, and chunking interaction was close to, but did not reach, significance.

Finally, the statistical analysis revealed a third-order interaction between delay, presentation rate, personalization, and chunking: The pattern observed for the interaction of delay, presentation rate, and personalization described above (see Fig. 5) was also found for the chunked condition, with an interaction between delay and personalization for the fasterpresentation-rate group, $\chi^{2}(1, N=39)=9.73, p=.002, \eta^{2}=.03$, and no interaction for the slower-rate group, $\chi^{2}(1, N=36)=$ 
Fig. 1 Mean recall of objects as a function of personalization and serial position. The error bars are standard errors

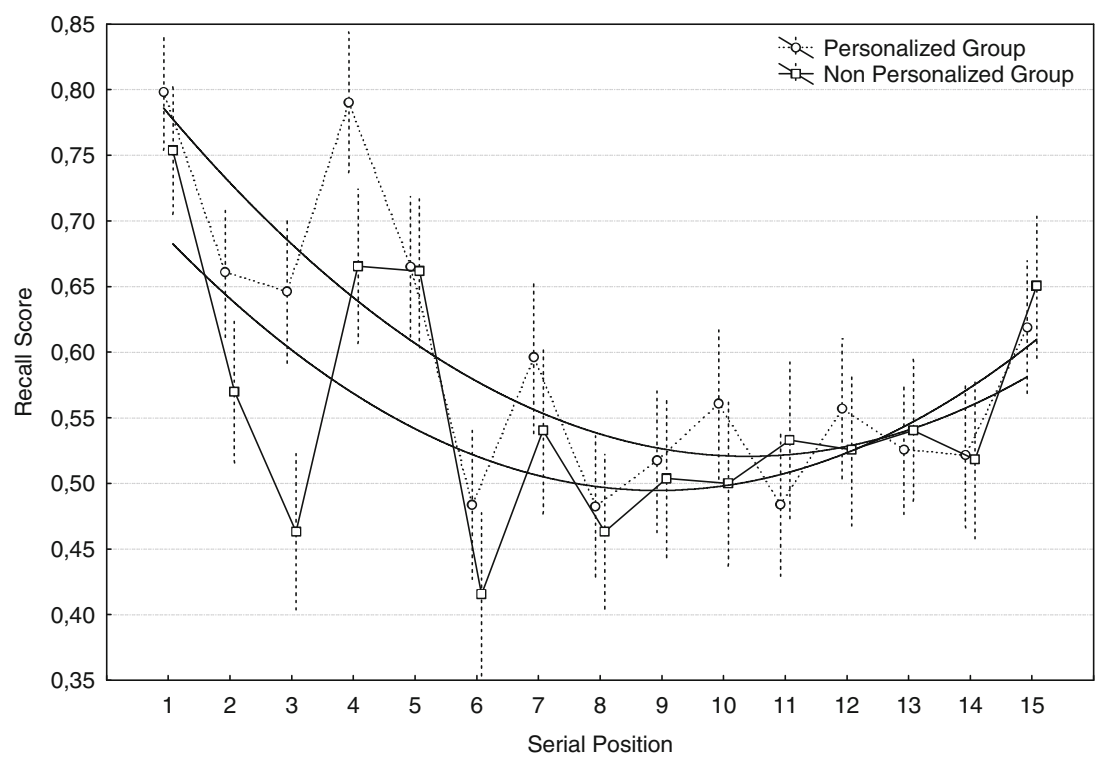

1.56, n.s., $\eta^{2}=.01$. A different pattern was observed for the unchunked condition, with no interaction between delay and personalization, no matter whether the presentation rate was $5 \mathrm{~s}$, $\chi^{2}(1, N=39)=0.23$, n.s., $\eta^{2}=0$, or $10 \mathrm{~s}, \chi^{2}(1, N=36)=0.01$, n.s., $\eta^{2}=0$.

More simply, and breaking down these results to delay effects (see Table 3), when presentation was slower, there was no effect of delay, no matter the kind of personalization or whether the information was chunked or unchunked. When presentation was faster, there was always an effect of delay, except when the information was chunked and personalized.

As suggested by a reviewer, we carried out an itemlevel analysis that revealed results comparable to those of the subjects analysis, and the significant results did not change.

Fig. 2 Mean recall of objects as a function of presentation rate and serial position. The error bars are standard errors
Supplementary analysis adding one external measure: The averaged $z$ scores of verbal and visuospatial working memory tasks

The same statistical analyses were performed, but adding the averaged $z$ scores of verbal and visuospatial WM measures, in order to test the hypothesis that WM span would interact with serial position in a similar way to personalization.

The results showed that the main effects that had been significant in the first analysis were still significant (for the results of the second analysis in extensor, see Table 2 of the supplementary materials). WM span had a main effect, in which more objects were recalled as WM span increased, $\chi^{2}(1, N=75)=10.29, p<.005, \eta^{2}=.01$.

With regard to the hypothesized interaction, our results showed a significant interaction between serial position and

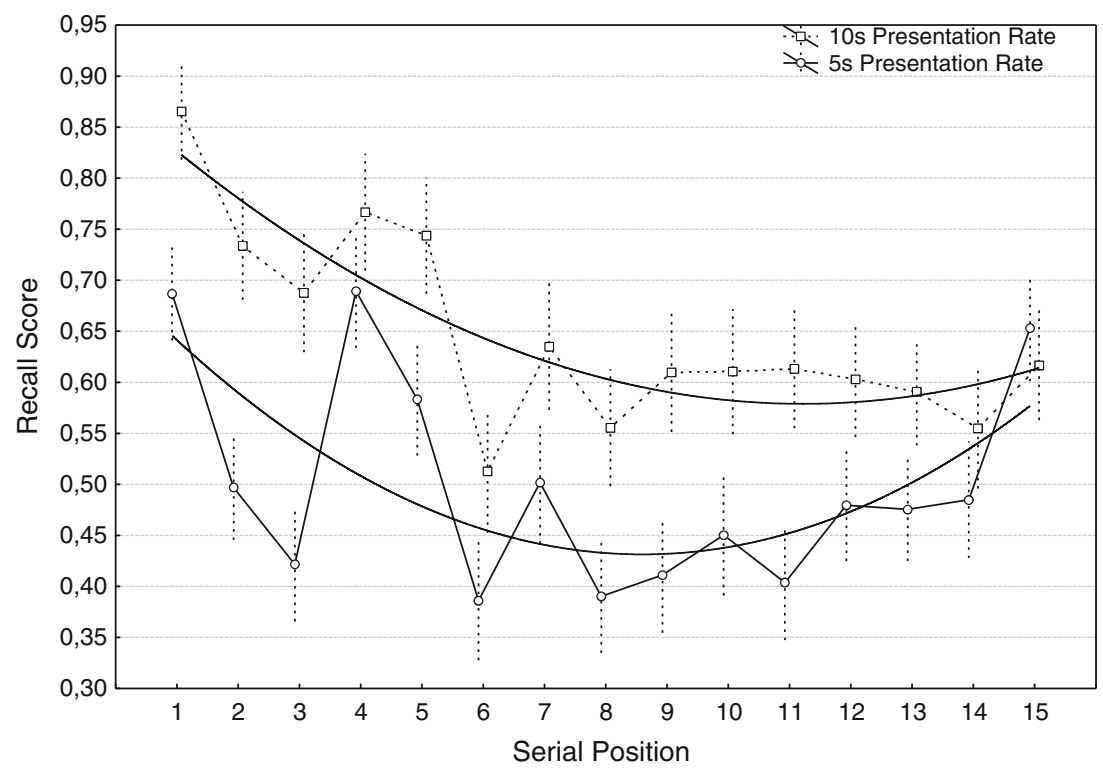



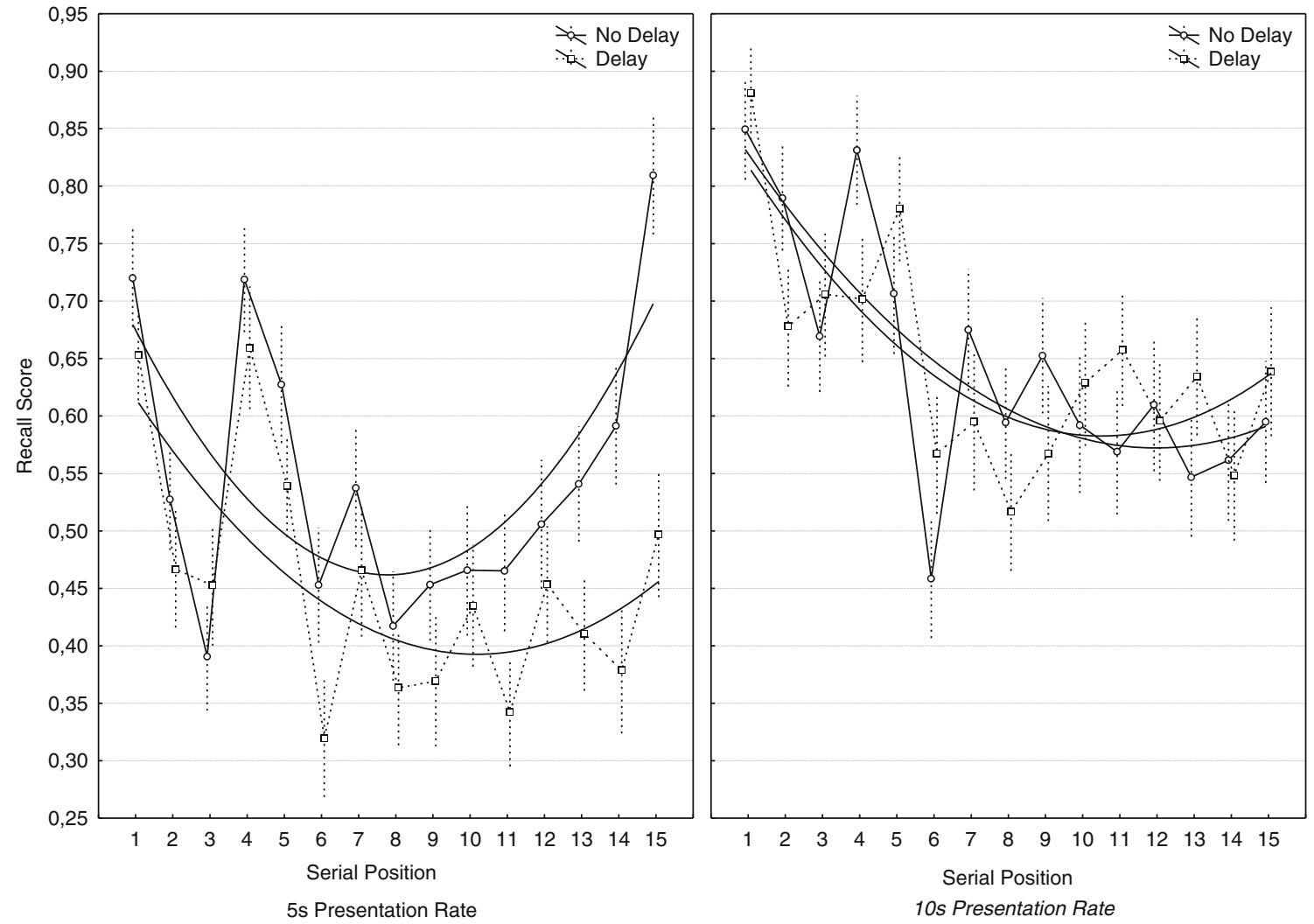

Fig. 3 Mean recall of objects as a function of presentation rate, delay, and serial position. The error bars are standard errors

WM span size, $\chi^{2}(2, N=75)=27.7, p<.0001, \eta^{2}=.05$. Figure 6 reveals that, after we dichotomized WM span for graphical purposes, the difference in recall scores between the high- and low-WM-span groups tended to become null on the recency part of the curve. This pattern was predicted by the LT-WM theory.
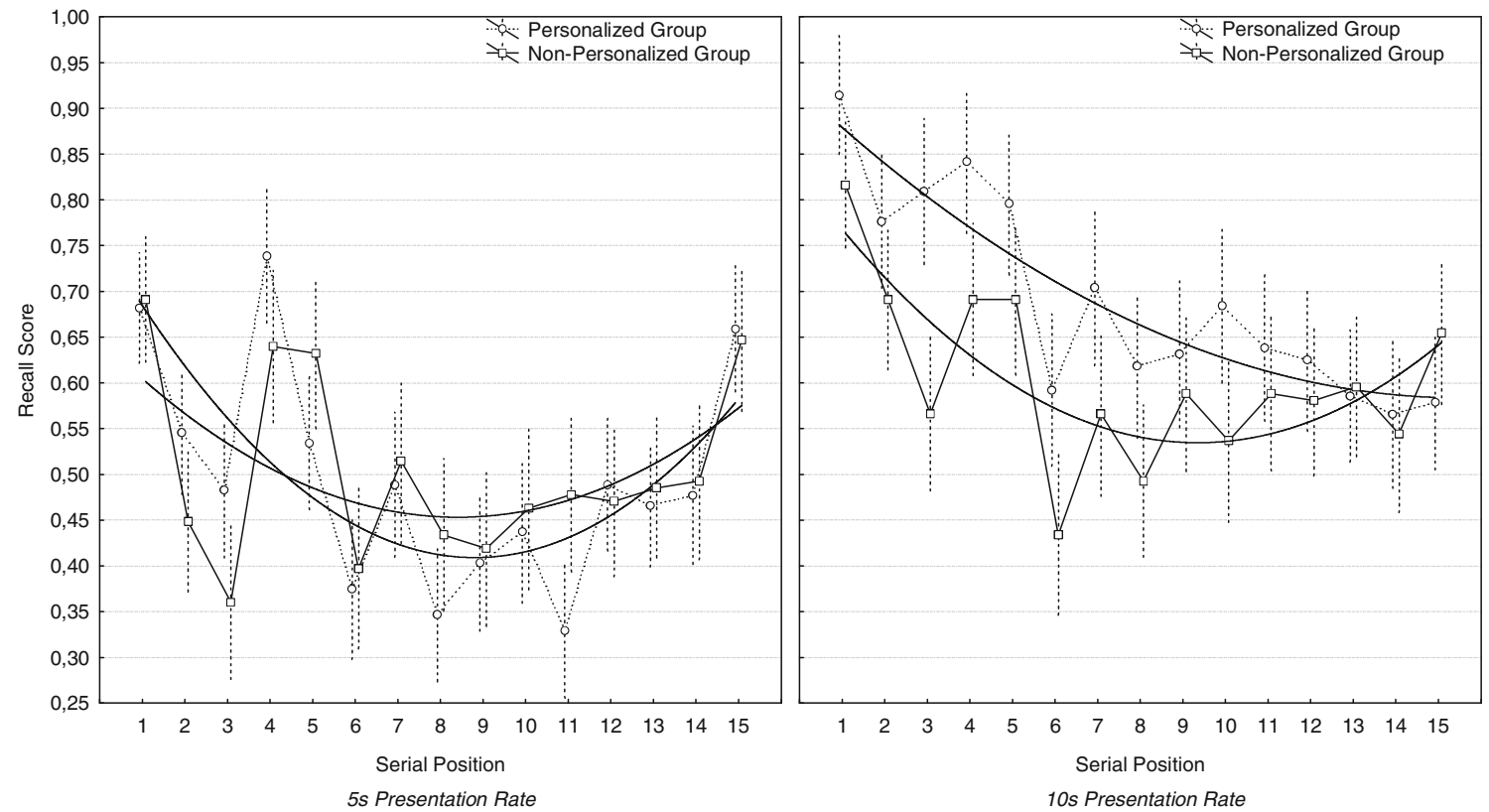

Fig. 4 Mean recall of objects as a function of presentation rate, personalization, and serial position. The error bars are standard errors 


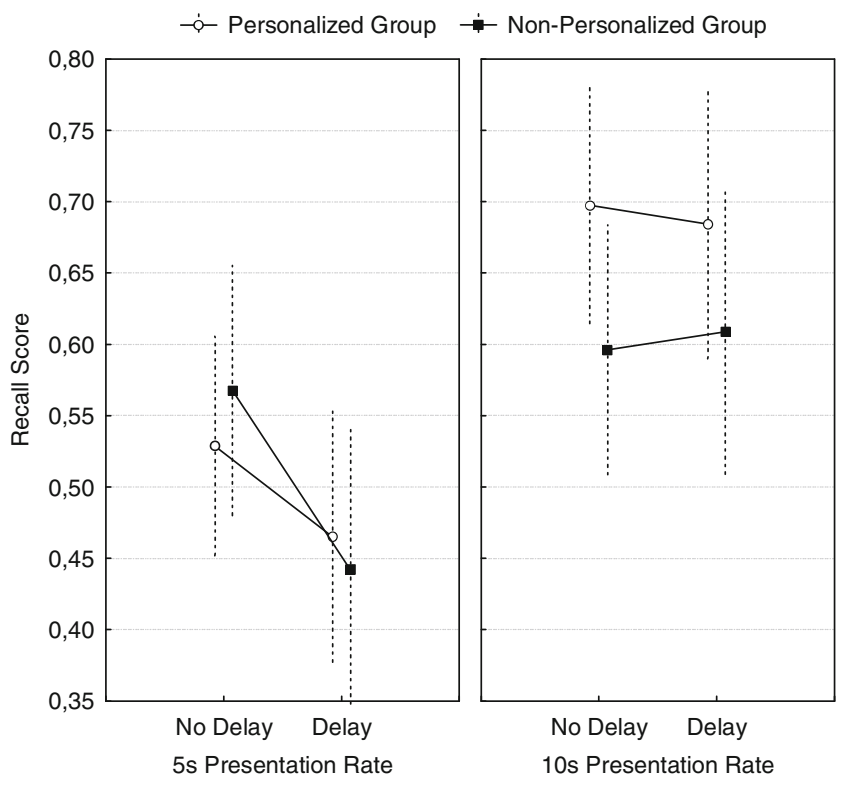

Fig. 5 Mean recall of objects as a function of presentation rate, delay, and personalization. The error bars are standard errors

For the rest of the analysis (see Table 2 of the supplementary materials), all of the effects that were significant in the first analysis were still significant in the second analysis, except the interaction between personalization, presentation rate, and serial position. Otherwise, the external measure did not alter the significance of the contributions of the factors tested in the first analysis.

\section{Discussion}

The main purpose of our study was to apply the personalization method (Guida \& Tardieu, 2005; Guida et al., 2009) to a free-recall task and to study the differential benefits of personalization according to an item's position in the serial curve. To this end, participants were shown 15 pairs of words, comprising a location and an object that they were asked to associate mentally. They then had to recall the objects. Prior to the task, participants in the personalized group were given information that the locations (e.g., a university cafeteria) were places that they knew (e.g., the cafeteria of their university), while the nonpersonalized group were told that the locations were unknown (supposedly at Erevan in Armenia). In brief, on the basis of the classic STM-LTM account of the serial position effect, the rationale was that if personalization operationalizes LT-WM (Ericsson \& Kintsch, 1995) - in other words, the capacity to encode and retrieve information from LTM reliably and rapidly - then the effect of personalization should be greater for the items of the curve that are putatively placed in LTM - the pre-recency effect items - as compared to the recency effect items.

We also introduced two factors, Presentation Rate and Delay, that are known to tap STM and LTM differentially, and two WM measures to test whether high span-low span differences are related to LTM, as is suggested by LT-WM theory (Ericsson \& Kintsch, 1995). According to this theory, high-span individuals score higher because they can encode and retrieve the items to be remembered from LTM, whereas low-spans rely mainly on their ST-WM.

\section{Explaining the effect of personalization}

Concerning the main point of the study, it clearly appeared that the effect of personalization varied according to the position of the items in the serial curve. As expected, the effect of personalization was greater for pre-recency effect items relative to recency effect items; the effect of personalization on the latter was insignificant. The traditional interpretation (e.g., Guida \& Tardieu, 2005; Guida et al., 2009) of the personalization effect suggests that during the presentation phase, participants in the personalized group use their knowledge of the locations to elaborately associate

Table 3 Mean recall of objects and the effect of delay as a function of chunking, presentation rate, and personalization

\begin{tabular}{|c|c|c|c|c|c|c|c|}
\hline & Presentation Rate & Personalized & No Delay & Delay & $\chi^{2}$ & $\mathrm{p}$ & $\eta^{2}$ \\
\hline \multirow[t]{4}{*}{ Chunked } & \multirow[t]{2}{*}{$5 \mathrm{~s}$} & No & $.62(.16)$ & $.45(.18)$ & 23.89 & $<.0001$ & .08 \\
\hline & & Yes & $.54(.18)$ & $.51(.2)$ & 0.68 & .41 & 0 \\
\hline & \multirow[t]{2}{*}{$10 \mathrm{~s}$} & No & $.62(.19)$ & $.62(.21)$ & 0.02 & .9 & 0 \\
\hline & & Yes & $.72(.20)$ & $.67(.19)$ & 3.49 & .06 & .01 \\
\hline \multirow[t]{4}{*}{ Unchunked } & \multirow[t]{2}{*}{$5 \mathrm{~s}$} & No & $.51(.11)$ & $.42(.20)$ & 5.23 & $<.05$ & .02 \\
\hline & & Yes & $.52(.10)$ & $.44(.12)$ & 9.71 & $<.005$ & .03 \\
\hline & \multirow[t]{2}{*}{$10 \mathrm{~s}$} & No & $.57(.24)$ & $.60(.21)$ & 0.66 & .42 & 0 \\
\hline & & Yes & $.67(.21)$ & $.70(.23)$ & 0.85 & .36 & 0 \\
\hline
\end{tabular}

Numbers in parentheses are standard deviations. The degrees of freedom were all 1 
Fig. 6 Mean recall of objects as a function of working memory span group and serial position. The error bars are standard errors

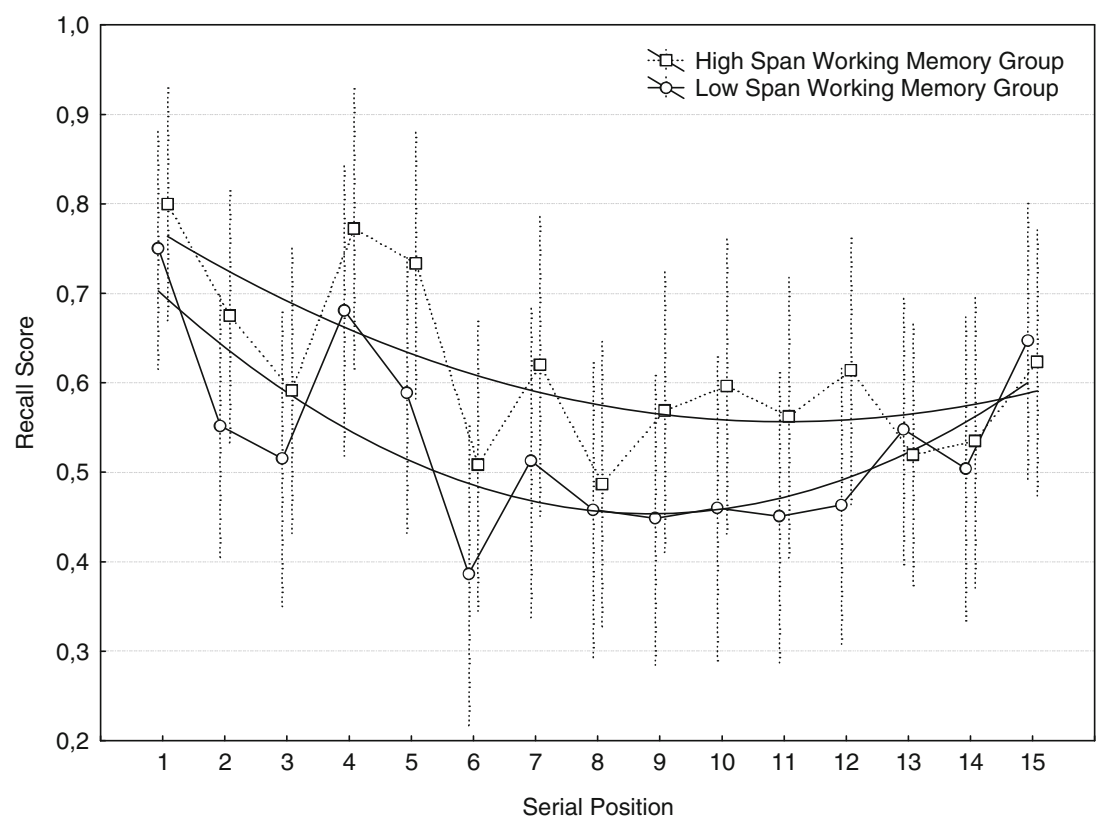

each object to be recalled with each location. In terms of LTWM theory, this group encodes incoming information (the objects) in a retrieval structure composed of retrieval cues (the locations) that they can reinstate during the recall phase (Tulving \& Thomson, 1973) for accurate recall of the objects. Conversely, the nonpersonalized group did not know the locations, which therefore could not be used efficiently as a retrieval structure.

However, in this study, the personalization effect varied according to serial position. Our interpretation of this novel finding is based on the classic STM-LTM account of the serial effect (for an account of serial-position effects using this approach, see Davelaar et al., 2005). In the dual-store approach, a $U$ shape is obtained because the probability of items entering LTM decreases the farther one goes from the first position, and hence, recall decreases because the items cannot be held in STM. Toward the final positions, recall increases because there is a greater probability of items entering and remaining in STM. Combining this approach with LT-WM theory helps us understand why the personalization effect varied according to the item's position. Since personalization is thought to trigger the use of a retrieval structure (in this case, knowledge of the locations), which allows items to be encoded and retrieved from LTM more rapidly and reliably, the effect of personalization was expected to be more effective on the LTM part of the curve, since personalization allows a switch from a classic LTM encoding to an elaborate LTM encoding. But since, as one advances through the positions, the capacity to encode items in LTM decreases, it was also expected that the capacity to encode elaborately - thanks to personalization-in LTM would decrease. This was the case. Finally, since performance is essentially related to STM toward the final positions, and no longer involves LTM encoding and retrieval, no advantage from personalization was expected, which was confirmed by the data.

The dual-store approach is not the only framework that can be used to interpret serial-position effects. While Davelaar et al. (2005) provided strong evidence for an STM-LTM dichotomy, two families of single-store models of memory have also provided compelling arguments. The first family assumes that the probability of recall depends on the distinctiveness of an item along a temporal or positional dimension (e.g., Brown et al., 2007; Nairne et al., 1997). In this case, the more that an item can be said to be distinctive relative to the occurrence of other presented items, the greater the probability of recall. This distinctiveness of items explains why those in extreme positions (the end or beginning of lists) are recalled better. This principle could also explain the effect of personalization, which makes the locations, and thus the objects linked to them, more distinctive. However, following this line of reasoning does not explain why distinctiveness would only have an impact on the beginning of the curve (LTM, in a dual-store approach), as there is no difference between LTM and STM in these distinctiveness-based models.

The second family of single-store models (e.g., Howard \& Kahana, 1999, 2002) is based on context variability between encoding and retrieval, but they seem to run into the same problem. In these models, items are associated with different (internal and/or external) contextual elements during the encoding phase. At retrieval, recall is based on the similarity between the retrieval context and the presentation context for each item, and a cue-dependent search process is required to retrieve information from LTM. Good retrieval is conditioned by limiting the search process to 
relevant information through the use of pertinent cues. Following this line of argument, the advantage of personalization can be interpreted as follows: When the locations are personalized, the search process is more effective because they provide better mental cues to refine the mental search process. While it is easy to understand the general advantage of personalization using this principle, it appears more difficult to understand the differential impact of personalization, whereby the advantage of personalization should occur for all positions, which was not the case in our study.

Other explanations that are not strictly mnemonic could also account for the differential effect of personalization on recall. It has been known at least since Hogan (1975) that the probability of first recall (PrFR) plays a role in terms of serial-position effects, and Howard and Kahana (1999) have highlighted the importance of the PrFR of the first item, observing that the probability of starting with the first item of a list is higher after a delay, when recall depends massively on pre-recency items.

Therefore, as was suggested by a reviewer, the PrFR of the first item could play an interesting role in the primacy effect. In other words, when participants start recall with the first item, it could increase the probability of observing a primacy effect. If this is true, one possibility is that personalization has only an indirect effect on the primacy effect, by increasing the PrFR of the first item, which in turn increases the primacy effect. To test this possibility, a first step in this causal chain would be to check whether, in our study, personalization had an effect on the PrFR of the first item. However, the difference between the personalized $(M=.23$, $S D=.24)$ and nonpersonalized $(M=.22, S D=.22)$ groups in the PrFR of the first item was nonsignificant, $t(73)=0.16$, n.s. Therefore, the differential effect of personalization on recall does not seem to be due to the fact of starting recall with the first item.

\section{Presentation rates, delay, and chunking}

A similar pattern to that of personalization was obtained by varying the presentation rate; in other words, slowing down the presentation rate constituted an advantage, which decreased through serial positions. This can be explained by the dual-store framework, whereby, if personalization accelerates encoding in LTM and increases the probability of LTM storage through the use of retrieval structures, then giving participants more time to encode information into LTM should have a similar effect. This was indeed the case. This pattern has been observed relatively often in the literature (e.g., Bonanni, Pasqualetti, Caltagirone, \& Carlesimo, 2007; Glanzer \& Cunitz, 1966; Raymond, 1969; Roberts, 1972; Tan \& Ward, 2000). However, in our case the effect was also found for items in the middle of the curve and those toward the end. As a consequence, we found very little recency effect at a 10-s presentation rate (Fig. 2). This unusual recency effect appears to be due partly to the presentation rate, which is rather long and unusual (to our knowledge, no other experiment has used such long encoding rates to study serial-position effects), and partly to personalization. Figure 4 shows that when personalization and a 10 -s presentation rate are combined, the curve is no more a curve but a straight line (this is the only curve that is modeled better by a linear than a quadratic function). This interaction between personalization and encoding rate as a function of serial positions was expected, as slowing down the presentation rate was predicted to increase the probability of an effect of personalization on pre-recency effect items, because it would give the personalized group more time to mentally instantiate the locations and to elaborately encode the objects in LTM.

However, what was not expected was that personalization would not be effective at all at a presentation rate of $5 \mathrm{~s}$. As we outlined in the introduction, personalization was conceived to be similar to the method of loci. However, at least two important elements differed between our paradigm and the method of loci. First, in the standard method-of-loci procedure, participants usually receive longer training to use the locations. We only used a short familiarization phase. Second, in the standard procedure, it is the participants who choose the familiar locations to be used. This was not possible in the location personalization paradigm. It is likely that these elements made it difficult for the participants to carry out the encoding process efficiently (meaning, in order to increase recall performance) with a 5 -s presentation time.

The rate of presentation was also crucial for the effect of delay, but in the opposite way from personalization, as we found no effect when presentation was at a rate of $10 \mathrm{~s}$. In terms of dual-store models, the interpretation appears straightforward: When the presentation slows down (10 s), the probability for the items to be encoded into LTM increases, even for the last items - hence, the absence of an effect of delay. We think that this absence of effect could be used as an interesting indicator of a strong reliance on LTM encoding and retrieval. This idea has already been put forward in the domain of expertise (Ericsson \& Kintsch, 1995; Gobet \& Simon, 1996b, 1998).

While no effect of delay emerged at $10 \mathrm{~s}$, there was one at $5 \mathrm{~s}$, and among the four groups of participants - that is, crossing personalization and presentation rate-the effect of delay was the highest when the 5-s presentation rate was coupled with no personalization. Again, this makes sense if the LT-WM theory and the dual-store framework are combined, since it corresponds to the group that putatively relies less on LTM (no personalization and faster encoding rates prevent efficient LTM encoding), and thus most on STM for recall performance-hence, the greatest effect of delay. 
As for the interplay between delay, personalization, and chunking, it is interesting to note, as is shown by Table 3, that in one condition there was no effect of delay even at the 5 -s presentation rate at which the effect was greatest-namely, when the locations were displayed in a chunked way for the personalized group. Again, if one takes the absence of an effect of delay as an indicator of reliance on LTM encoding and retrieval, this suggests that when combined with personalization, chunking increased the probability of the items being transferred to LTM. This is understandable, since the chunked presentation of the items during the presentation phase was meant to help participants chunk the objects and link them more efficiently to the locations. In the case of the personalized locations, this linking process was expected to enhance encoding and retrieval from LTM. For the same reason, we predicted that chunking would accentuate the differential effect of personalization on the primacy and recency effects, leading to an interaction between personalization, serial position, and chunking. However, this interaction was only marginal $(p=.06)$. Apart from the interaction described above, chunking did not interact with the other factors.

With regard to its main effect, the results showed that chunked presentation led to better performance than did the unchunked condition. One possible interpretation is that the chunked condition presented an advantage, in that chunking is thought to contribute to an integrated representation favoring chunked processing of the objects (e.g., Cowan et al., 2004; Gobet et al., 2001). However, part of the effect could also have been caused by the disadvantage of the unchunked condition, in that the locations that could be used as cues during recall were not congruent with the temporal (or positional) distance between the items. ${ }^{1}$ In other words, participants in the unchunked condition might have reorganized the items in a chunked fashion, leading to a mismatch between the input (items during the presentation phase) and output (items during the recall phase). To check this possibility, we used the adjusted ratio of clustering (ARC) score (Roenker, Thompson, \& Brown, 1971), which computes a clustering or chunking score. If the ARC score of a participant is different from zero, this indicates that the output recall of that participant is clustered, or in our case "chunked," according to the locations of the presentation phase. The mean ARC score was .31 ( $S D=$ .31 ) for the unchunked condition (0 indicates no clustering, 1 perfect clustering), suggesting that the participants in the unchunked condition reorganized the items in a chunked fashion.

\footnotetext{
${ }^{1}$ We thank an anonymous reviewer for this suggestion.
}

Personalization: Organization and/or elaboration? ${ }^{2}$

The results discussed above clearly show that the information was reorganized in terms of chunks, especially in the unchunked condition. Could this shed light on the personalization effect that we analyzed earlier? This seems likely, knowing the crucial role played by "organization" in mnemonic phenomena (e.g., Bellezza, Cheesman, \& Reddy, 1977; Craik, 1979; Pressley et al., 1992; Shing, Werkle-Bergner, Li, \& Lindenberger, 2008). More specifically, organization (i.e., the encoding of relationships between list items) and elaboration (i.e., the encoding of individual characteristics) seem to play a crucial role in the increase of mnemonic efficiency when they are combined (e.g., Burns, Burns, \& Hwang, 2011; Einstein \& Hunt, 1980; Hunt \& Einstein, 1981; Klein \& Loftus, 1988).

If the personalization effect was due to an increase of organization, it should be possible to detect this by comparing the personalized and nonpersonalized groups. Using the ARC score, we measured differences in organization in terms of chunks. The difference between the personalized $(M=.42, S D=.25)$ and nonpersonalized $(M=.49, S D=$ $.24)$ groups was nonsignificant, $t(73)=1.33$, n.s. And the same result was observed, $t(73)=1.03$, n.s., when the same analysis was restricted to the unchunked condition, in which the input was not already organized in chunks. Thus, our statistical data do not indicate a reorganization that could explain the personalization effect.

The involvement of elaboration in the personalization effect is more difficult to detect a posteriori. One way to detect it is by tracking the effort of encoding via questionnaires or measuring encoding time (e.g., Klein, Robertson, \& Delton, 2010; Nairne, Thompson, \& Pandeirada, 2007), with more time putatively meaning more elaboration. In our study, such data were not gathered; however, we did vary encoding times, observing that the effect of personalization only appeared at $10 \mathrm{~s}$. This could be interpreted as evidence that efficient personalization needs enough time to involve elaboration.

In conclusion, our data suggest that the personalization effect does not stem from a combination of elaboration and organization, but likely from a difference in terms of elaboration.

\section{LT-WM and WM span}

When proposing the LT-WM theory, Ericsson and Kintsch (1995) suggested that the differences between high- and low-WM-span individuals are at least partly due to the capacity to encode and retrieve information from LTM. If this is true, and taking the dual-store approach as a framework, the difference between the serial-recall curves of

\footnotetext{
${ }^{2}$ We thank Geoff Ward for drawing our attention to the similarities between personalization and processing effects concerning essential processes such as elaboration and organization.
} 
high- and low-span individuals should appear more in the LTM part of the curve. Our results are in line with this prediction. Our interpretation is that the capacity to encode and retrieve items from LTM gives high-span individuals an advantage over low-span individuals. Our results support the findings of Unsworth and colleagues, who compared the performance of high- and low-span individuals in free-recall tasks, using a composite WM score. From their work, it appears that low-span individuals "tend to have recall deficits associated with pre-recency items compared to controls or individuals with high working memory capacities, while recall of recency items is roughly the same" (Unsworth, Brewer, \& Spillers, 2011a, p. 68). This trend was found with free recall (Unsworth \& Engle, 2007), delayed free recall (Unsworth, 2007, Exp. 1), and continuous-distractor free recall (Unsworth \& Spillers, 2010; but see Unsworth, 2007, Exp. 2).

Some other work from Unsworth and colleagues (Unsworth, Brewer, \& Spillers, 2011b; Unsworth \& Spillers, 2010) can also help shed light on the LT-WM construct through the differences between low- and high-span individuals. Unsworth and Spillers observed that high- and low-span individuals had similar recall scores with a continuous-distractor free-recall paradigm, but only when encoding was incidental; when encoding was intentional, the usual high-span advantage was found. Moreover, the advantage of the intentional condition was particularly strong for the primacy-effect (LTM) items. This clearly shows that when one is looking for crucial differences that can explain high span-low span differences, LTM encoding is important, and this process is intentional. This was confirmed by Unsworth et al. (2011b), who showed that a mismatch between encoding and retrieval lowered the performance of high-span individuals more than that of low-span individuals. Taking these last results together, it appears that concerning the differences between high and low spans, the process of encoding and retrieving from LTM is crucial. This is of particular interest with regard to our interpretation of personalized/nonpersonalized differences, which were focused on LTM encoding and retrieval processes.

\section{Conclusion}

Capitalizing on a previous finding (Guida et al., 2009) in which we showed that personalization increased reading span, the main purpose of this study was to confirm that this increase via personalization was due to LTM storage. To do so, we used free recall, which we argued allows for separating STM from LTM, and observed, as expected, that personalization increased only LTM. We believe that this is an important step toward validating the personalization method as a method for characterizing the contribution of LTM storage to performance in working memory tasksthat is, LT-WM, in Ericsson and Kintch's (1995) terms.
Author note Hubert Tardieu, our dear friend, collaborator, and colleague passed away during the construction of this study. Without his impetus, the personalization method would never have been used to operationalize long-term working memory. We feel privileged to have shared moments of his life. We also thank Raphälle Tritschler, Margot Chomard, and Benjamin Le Henaff for assistance during data collection. Finally, we thank Larry David for suggesting the title via his television series.

\section{References}

Anderson, J. R., Reder, L. M., \& Lebiere, C. (1996). Working memory: Activation limitations on retrieval. Cognitive Psychology, 30, 221-256.

Baddeley, A. (1986). Working memory. Oxford: Oxford University Press, Clarendon Press.

Baddeley, A. (2000). The episodic buffer: A new component of working memory? Trends in Cognitive Sciences, 4, 417-423. doi:10.1016/S1364-6613(00)01538-2

Barrouillet, P., Bernardin, S., \& Camos, V. (2004). Time constraints and resource sharing in adults' working memory spans. Journal of Experimental Psychology. General, 133, 83-100. doi:10.1037/ 0096-3445.133.1.83

Bates, D., Maechler, M., \& Bolker, B. (2011). lme4: Linear mixedeffects models using S4 classes (R package version 0.999375-42) [Software]. Retrieved from http://CRAN.R-project.org/package= lme4

Bellezza, F. S. (1984). The self as a mnemonic device: The role of internal cues. Journal of Personality and Social Psychology, 47, 506-516. doi:10.1037/0022-3514.47.3.506

Bellezza, F. S., Cheesman, F. L., \& Reddy, G. (1977). Organization and semantic elaboration in free recall. Journal of Experimental Psychology: Human Learning and Memory, 1, 539-550.

Bellezza, F. S., \& Reddy, B. G. (1978). Mnemonic devices and natural memory. Bulletin of the Psychonomic Society, 11, 277-280.

Bonanni, R., Pasqualetti, P., Caltagirone, C., \& Carlesimo, G. A. (2007). Perceptual and Motor Skills, 105, 483-500.

Brown, G. D. A., Neath, I., \& Chater, N. (2007). A temporal ratio model of memory. Psychological Review, 114, 539-576. doi:10.1037/0033-295X.114.3.539

Burns, D. J., Burns, S. A., \& Hwang, A. J. (2011). Adaptive memory: Determining the proximate mechanisms responsible for the memorial advantage of survival processing. Journal of Experimental Psychology: Learning, Memory, and Cognition, 37, 206-218. doi: $10.1037 / \mathrm{a} 0021325$

Chase, W. G., \& Ericsson, K. A. (1982). Skill and working memory. In G. H. Bower (Ed.), The psychology of learning and motivation (Vol. 16, pp. 1-58). New York: Academic Press.

Chen, Z., \& Cowan, N. (2005). Chunk limits and length limits in immediate recall: A reconciliation. Journal of Experimental Psychology: Learning, Memory, and Cognition, 31, 1235-1249. doi:10.1037/0278-7393.31.6.1235

Cowan, N. (1995). Attention and memory: An integrated framework. New York: Oxford University Press.

Cowan, N. (2001). The magical number 4 in short-term memory: A reconsideration of mental storage capacity. The Behavioral and Brain Sciences, 24, 87-114. doi:10.1017/S0140525X01003922. disc. 115-185.

Cowan, N. (2005). Working memory capacity. Hove: Psychology Press.

Cowan, N., Chen, Z., \& Rouder, J. N. (2004). Constant capacity in an immediate serial-recall task: A logical sequel to Miller (1956). Psychological Science, 15, 634-640. doi:10.1111/j.09567976.2004.00732.x 
Craik, F. I. M. (1970). The fate of primary memory items in free recall. Journal of Verbal Learning and Verbal Behavior, 9, 143-148.

Craik, F. I. M. (1979). Human memory. Annual Review of Psychology, $30,63-102$.

Daneman, M., \& Carpenter, P. A. (1980). Individual differences in working memory and reading. Journal of Verbal Learning and Verbal Behavior, 19, 450-466. doi:10.1016/S0022-5371 (80)90312-6

Davelaar, E. J., Goshen-Gottstein, Y., Ashkenazi, A., Haarmann, H. J., \& Usher, M. (2005). The demise of short-term memory revisited: Empirical and computational investigations of recency effects. Psychological Review, 112, 3-42. doi:10.1037/0033295X.112.1.3

De Beni, R., \& Comoldi, C. (1988). Does the repeated use of loci create interference? Perceptual and Motor Skills, 67, 415-418.

De Beni, R., \& Cornoldi, C. (1985). Effects of the mnemotechnique of loci in the memorization of concrete words. Acta Psychologica, $60,11-24$

Desmette, D., Hupet, M., Schelstrate, M. A., \& van der Linden, M. (1995). Adaptation en langue française du "Reading Span Test" de Daneman et Carpenter (1980). L'Année Psychologique, 95, 459-482.

Desrochers, A., \& Bergeron, M. (2000). Valeurs de fréquence subjective et $d$ 'imagerie pour un échantillon de 1016 substantifs de la langue française. Revue Canadienne de Psychologie Expérimentale, 54, 274-325.

Einstein, G. O., \& Hunt, R. R. (1980). Levels of processing and organization: Additive effects of individual-item and relational processing. Journal of Experimental Psychology: Human Learning and Memory, 6, 588-598.

Ericsson, K. A. (1985). Memory skill. Canadian Journal of Psychology, 39, 188-231.

Ericsson, K. A., \& Kintsch, W. (1995). Long-term working memory. Psychological Review, 102, 211-245. doi:10.1037/0033295X.102.2.211

Ericsson, K. A., \& Kintsch, W. (2000). Shortcomings of generic retrieval structures with slots of the type of Gobet (1993) proposed and modelled. British Journal of Psychology, 91, 571-590.

Gardiner, M., Thompson, C. P., \& Maskarinec, A. S. (1974). Negative recency in initial free recall. Journal of Experimental Psychology, 103, 71-78.

Glanzer, M., \& Cunitz, A. R. (1966). Two storage mechanisms in free recall. Journal of Verbal Learning and Verbal Behavior, 5, 351360. doi:10.1016/S0022-5371(66)80044-0

Gobet, F. (2000a). Retrieval structures and schemata: A brief reply to Ericsson and Kintsch. British Journal of Psychology, 91, 591594.

Gobet, F. (2000b). Some shortcomings of long-term working memory. British Journal of Psychology, 91, 551-570.

Gobet, F., Lane, P. C. R., Croker, S., Cheng, P. C. H., Jones, G., Oliver, I., \& Pine, J. M. (2001). Chunking mechanisms in human learning. Trends in Cognitive Sciences, 5, 236-243.

Gobet, F., \& Simon, H. A. (1996a). Recall of random and distorted positions: Implications for the theory of expertise. Memory \& Cognition, 24, 493-503.

Gobet, F., \& Simon, H. A. (1996b). Templates in chess memory: A mechanism for recalling several boards. Cognitive Psychology, $31,1-40$.

Gobet, F., \& Simon, H. A. (1998). Expert chess memory: Revisiting the chunking hypothesis. Memory, 6, 225-255.

Guida, A., Gobet, F., Tardieu, H., \& Nicolas, S. (2012). How chunks, long-term working memory and templates offer a cognitive explanation for neuroimaging data on expertise acquisition: A twostage framework. Brain and Cognition, 79, 221-244.

Guida, A., \& Tardieu, H. (2005). Is personalisation a way to operationalise long-term working memory? Current Psychology Letters:
Behaviour, Brain and Cognition, 15, 1-17. Retrieved from http:// cpl.revues.org/document439.html

Guida, A., Tardieu, H., \& Nicolas, S. (2009). The personalisation method applied to a working memory task: Evidence of longterm working effects. European Journal of Cognitive Psychology, 21, 862-896.

Hambrick, D., \& Engle, R. (2002). Effects of domain knowledge, working memory capacity, and age on cognitive performance: An investigation of the knowledge-is-power hypothesis. Cognitive Psychology, 44, 339-387.

Hambrick, D., \& Oswald, F. (2005). Does domain knowledge moderate involvement of working memory capacity in higher-level cognition? A test of three models. Journal of Memory and Language, 52, 377-397.

Hatano, G., \& Osawa, K. (1983). Digit memory of grand experts in abacus-derived mental calculation. Cognition, 15, 95-110.

Hogan, R. M. (1975). Interitem encoding and directed search in free recall. Memory \& Cognition, 3, 197-209.

Howard, M. W., \& Kahana, M. J. (1999). Contextual variability and serial position effects in free recall. Journal of Experimental Psychology: Learning, Memory, and Cognition, 25, 923-941. doi: $10.1037 / 0278-7393.25 .4 .923$

Howard, M. W., \& Kahana, M. J. (2002). A distributed representation of temporal context. Journal of Mathematical Psychology, 46, 269-299. doi:10.1006/jmps.2001.1388

Hulme, C., Maughan, S., \& Brown, G. D. (1991). Memory for familiar and unfamiliar words: Evidence for a long-term memory contribution to short-term memory span. Journal of Memory and Language, 30, 685-701.11.

Hulme, C., Newton, P., Cowan, N., Stuart, G., \& Brown, G. (1999). Think before you speak: Pauses, memory search, and trace reintegration processes in verbal memory span. Journal of Experimental Psychology: Learning, Memory, and Cognition, 25, 447463.

Hunt, R. R., \& Einstein, G. O. (1981). Relational and item-specific information in memory. Journal of Verbal Learning and Verbal Behavior, 20, 497-514.

Jaeger, T. F. (2008). Categorical data analysis: Away from ANOVAs (transformation or not) and towards logit mixed models. Journal of Memory and Language, 59, 434-446. doi:10.1016/ j.jml.2007.11.007

Jones, G., Gobet, F., \& Pine, J. M. (2007). Linking working memory and long-term memory: A computational model of the learning of new words. Developmental Science, 10, 853-873.

Jones, G., Gobet, F., \& Pine, J. M. (2008). Computer simulations of developmental change: The contributions of working memory capacity and long-term knowledge. Cognitive Science, 32, $1148-1176$.

Just, M. A., \& Carpenter, P. A. (1992). A capacity theory of comprehension: Individual differences in working memory. Psychological Review, 99, 122-149. doi:10.1037/0033-295X.99.1.122

Kellogg, R. T. (2001). Long-term working memory in text production. Memory \& Cognition, 29, 43-52. doi:10.3758/BF03195739

Klein, S. B., \& Loftus, J. (1988). The nature of self-referent encoding: The contributions of elaborative and organizational processes. Journal of Personality and Social Psychology, 55, 5-11.

Klein, S. B., Robertson, T. E., \& Delton, A. W. (2010). Facing the future: Memory as an evolved system for planning future acts. Memory \& Cognition, 38, 13-22. doi:10.3758/MC.38.1.13

Kuiper, N. A., \& Rogers, T. B. (1979). Encoding of personal information: Self-other differences. Journal of Personality and Social Psychology, 37, 499-514.

Masunaga, H., \& Horn, J. L. (2000). On the emergence of wisdom: Expertise development. In W. S. Brown (Ed.), Understanding wisdom: Sources, science, and society (pp. 245-276). Philadelphia: Templeton Foundation Press. 
Nairne, J. S., Neath, I., Serra, M., \& Byun, E. (1997). Positional distinctiveness and the ratio rule in free recall. Journal of Memory and Language, 37, 155-166. doi:10.1006/jmla.1997.2513

Nairne, J. S., Thompson, S. R., \& Pandeirada, J. N. S. (2007). Adaptive memory: Survival processing enhances retention. Journal of Experimental Psychology: Learning, Memory, and Cognition, 33, 263-273. doi:10.1037/0278-7393.33.2.263

New, B., Pallier, C., Brysbaert, M., \& Ferrand, L. (2004). Lexique 2: A new French lexical database. Behavior Research Methods, Instruments, \& Computers, 36, 516-524. doi:10.3758/BF03195598

Noel, Y. (2011). R2STATS: A GTK GUI for GLM and GLMM in R (R package version 0.68-29) [Software]. Retrieved from http:// cran. $r$-project.org/package $=\mathrm{R} 2 \mathrm{STATS}$

Oberauer, K. (2002). Access to information in working memory: Exploring the focus of attention. Journal of Experimental Psychology: Learning, Memory, and Cognition, 28, 411-421. doi:10.1037/0278-7393.28.3.411

Oberauer, K. (2005). Binding and inhibition in working memory: Individual and age differences in short-term recognition. Journal of Experimental Psychology. General, 134, 368-387. doi:10.1037/0096-3445.134.3.368

Poirier, M., \& Saint Aubin, J. (1995). Memory for related and unrelated words: Further evidence on the influence of semantic factors in immediate serial recall. Quarterly Journal of Experimental Psychology, 48A, 384-404.

Postal, V. (2004). Expertise in cognitive psychology: Testing the hypothesis of long-term working memory in a study of soccer players. Perceptual and Motor Skills, 99, 403-420.

Pressley, M., Wood, E., Woloshyn, V. E., Martin, V., King, A., \& Menke, D. (1992). Encouraging mindful use of prior knowledge: Attempting to construct explanatory answers facilitates learning. Educational Psychologist, 27, 91-109.

Quené, H., \& van den Bergh, H. (2008). Examples of mixed-effects modeling with crossed random effects and with binomial data. Journal of Memory and Language, 59, 413-425. doi:10.1016/ j.jml.2008.02.002

R Development Core Team. (2012). R: A language and environment for statistical computing [Computer software]. Vienna, Austria: R Foundation for Statistical Computing. Retrieved from www.Rproject.org

Radvansky, G. A., \& Zacks, R. T. (1991). Mental models and the fan effect. Journal of Experimental Psychology: Learning, Memory, and Cognition, 17, 940-953.

Raymond, B. J. (1969). Short-term storage and long-term storage in free recall. Journal of Verbal Learning and Verbal Behavior, 8, $567-574$.

Roberts, W. (1972). Free recall of words lists varying in length and rate of presentation: A test of total-time hypotheses. Journal of Experimental Psychology, 92, 365-372.

Roediger, R. L., III. (1980). The effectiveness of four mnemonics in ordering recall. Journal of Experimental Psychology: Human Learning and Memory, 6, 558-567.

Roenker, D. L., Thompson, C. P., \& Brown, S. C. (1971). Comparison of measures for the estimation of clustering in free recall. Psychological Bulletin, 76, 45-48.

Rogers, T. B., Kuiper, N. A., \& Kirker, W. S. (1977). Self-reference and the encoding of personal information. Journal of Personality and Social Psychology, 35, 677-688. doi:10.1037/0022-3514.35.9.677

Rose, N. S., Myerson, J., Roediger, H. L., III, \& Hale, S. (2010). Similarities and differences between working memory and longterm memory: Evidence from the levels-of-processing span task. Journal of Experimental Psychology: Learning, Memory, and Cognition, 36, 471-483.
Ross, J., \& Lawrence, K. A. (1968). Some observations on memory artifice. Psychonomic Science, 13, 107-108.

Schweickert, R. (1993). A multinomial processing tree model for degradation and redintegration in immediate recall. Memory \& Cognition, 21, 168-175.

Shing, Y. L., Werkle-Bergner, M., Li, S.-C., \& Lindenberger, U. (2008). Associative and strategic components of episodic memory: A lifespan dissociation. Journal of Experimental Psychology. General, 137, 495-513.

Sohn, Y. W., \& Doane, S. M. (2003). Roles of working memory capacity and long-term working memory skill in complex task performance. Memory \& Cognition, 31, 458-466.

Symons, C. S., \& Johnson, B. T. (1997). The self-reference effect in memory: A meta-analysis. Psychological Bulletin, 121, 371-394. doi:10.1037/0033-2909.121.3.371

Tan, L., \& Ward, G. (2000). A recency-based account of primacy effects in free recall. Journal of Experimental Psychology: Learning, Memory, and Cognition, 26, 1589-1625.

Towse, J. N., Cowan, N., Hitch, G. J., \& Horton, N. J. (2008). The recall of information from working memory: Insights from behavioural and chronometric perspectives. Experimental Psychology, $55,371-383$.

Tulving, E., \& Thomson, D. M. (1973). Encoding specificity and retrieval processes in episodic memory. Psychological Review, 80, 352-373. doi:10.1037/h0020071

Unsworth, N. (2007). Individual differences in working memory capacity and episodic retrieval: Examining the dynamics of delayed and continuous distractor free recall. Journal of Experimental Psychology: Learning, Memory, and Cognition, 33, 1020-1034.

Unsworth, N., Brewer, G. A., \& Spillers, G. J. (2011a). Inter- and intraindividual variation in immediate free recall: An examination of serial position functions and recall initiation strategies. Memory, 19, 67-82.

Unsworth, N., Brewer, G. A., \& Spillers, G. J. (2011b). Variation in working memory capacity and episodic memory: Examining the importance of encoding specificity. Psychonomic Bulletin \& Review, 18, 1113-1118. doi:10.3758/s13423-011-0165-y

Unsworth, N., \& Engle, R. W. (2007). The nature of individual differences in working memory capacity: Active maintenance in primary memory and controlled search from secondary memory. Psychological Review, 114, 104-132. doi:10.1037/0033295X.114.1.104

Unsworth, N., Heitz, R. P., Schrock, J. C., \& Engle, R. W. (2005). An automated version of the operation span task. Behavior Research Methods, 37, 498-505. doi:10.3758/BF03192720

Unsworth, N., \& Spillers, G. J. (2010). Variation in working memory capacity and episodic recall: The contributions of strategic encoding and contextual retrieval. Psychonomic Bulletin \& Review, 17, 200-205. doi:10.3758/PBR.17.2.200

Unsworth, N., Spillers, G. J., \& Brewer, G. A. (2010). The contributions of primary and secondary memory to working memory capacity: An individual differences analysis of immediate free recall. Journal of Experimental Psychology: Learning, Memory, and Cognition, 36, 240-247.

Verhaeghen, P., \& Kliegl, R. (2000). The effects of learning a new algorithm on asymptotic accuracy and execution speed in old age: A reanalysis. Psychology and Aging, 15, 648-656.

Was, C. A., \& Woltz, D. J. (2007). Reexamining the relationship between working memory and comprehension: The role of available long-term memory. Journal of Memory and Language, 56, 86-102. doi:10.1016/j.jml.2006.07.008

Yates, F. A. (1966). The art of memory. Chicago: University of Chicago Press. 